\title{
Prototipe Media Pembelajaran Rambu Lalu Lintas Berbasis Android
}

\author{
Andi Tejawati', Muhammad Bambang Firdaus ${ }^{2 *}$, Muhammad Nur Ihwan ${ }^{3}$, M Khairul Anam ${ }^{4}$, Faza $^{1}$ \\ Alameka $^{5}$ \\ ${ }^{1,2,3}$ Universitas Mulawarman \\ ${ }^{4}$ STMIK Amik Riau \\ ${ }^{5}$ Universitas Mulia \\ *bambangf@fkti.unmul.ac.id
}

\begin{abstract}
This study is motivated by motorists' lack of knowledge and discipline when it comes to traffic signs, which leads to frequent traffic accidents, congestion, and other issues on the road. The problem formulation is how to design and develop an Android-based traffic learning media application. The goal of this research is to provide motorists with information about road signs. The purpose of this research is to examine the literature on the theory of instructional media and the various types of android-based application development. The black box method was used to test this application. This study yielded an android-based traffic learning media application. Based on the test results, it is possible to conclude that this application was created to assist motorists in locating traffic signs on the highway.
\end{abstract}

Keywords: learning media, sign, traffic

\begin{abstract}
Abstrak
Studi ini dilatarbelakangi oleh kurangnya pengetahuan dan kedisiplinan pengendara dalam hal rambu lalu lintas, yang menyebabkan seringnya terjadi kecelakaan lalu lintas, kemacetan, dan masalah lain di jalan raya. Rumusan masalah tersebut adalah bagaimana merancang dan mengembangkan aplikasi media pembelajaran lalu lintas berbasis android. Tujuan dari penelitian ini adalah memberikan informasi kepada pengendara tentang rambu-rambu jalan raya. Tujuan dari penelitian ini adalah untuk mengkaji literatur tentang teori media pembelajaran dan berbagai jenis pengembangan aplikasi berbasis android. Metode kotak hitam digunakan untuk menguji aplikasi ini. Penelitian ini menghasilkan aplikasi media pembelajaran lalu lintas berbasis android. Berdasarkan hasil pengujian dapat disimpulkan bahwa aplikasi ini dibuat untuk membantu pengendara dalam mencari rambu lalu lintas di jalan raya.
\end{abstract}

Kata kunci: media pembelajaran, rambu, lalu lintas

\section{PENDAHULUAN}

Istilah "Lalu lintas dan angkutan jalan" mengacu pada kombinasi lalu lintas, angkutan jalan, dan jaringan lalu lintas. Pemerintah Indonesia mengupayakan lalu lintas dan transportasi jalan raya yang lancar, tertib, cepat, aman, efisien, dan nyaman. Hal ini dibuktikan dengan dibentuknya berbagai peraturan tentang tata tertib berlalu lintas, yaitu sebagai masyatakat Indonesia dituntut untuk mendukung tujuan pemerintah tersebut dengan cara menaati peraturan berlalu lintas yang telah dibuat. Namun masih terdapat pengendara yang melanggar aturan berlalu lintas.

Pelanggaran lalu lintas mayoritas disebabkan oleh pengendara yang kurang memahami dan mematuhi rambu lalu lintas. [1]. Jika pengemudi sudah terbiasa dengan rambu lalu lintas, kemungkinan besar ia akan mematuhi peraturan lalu lintas di Indonesia; Oleh karena itu, pengetahuan dan kesadaran disiplin lalu lintas harus ditanamkan pada usia muda [2].

Media pembelajaran merupakan salah satu alat yang digunakan guru untuk memfasilitasi kegiatan pembelajaran. Adanya 
media pembelajaran menjadikan proses belajar mengajar terasa lebih menarik, memupuk kemauan belajar, dan cara pengajaran menjadi lebih beragam sehingga mengurangi rasa bosan saat belajar [3].

Lebih lanjut, media pembelajaran membantu masyarakat dalam mempersiapkan dan menelaah bahan yang ada secara individu untuk pembelajaran dimanapun dan kapanpun. Setiap orang di dunia sekarang ini memiliki ponsel karena teknologi ini sangat berdampakbagi kehidupan kita sehari-hari.

Contoh dari hal itu adalah seperti sarana komunikasi dengan orang lain untuk mengetahui bagaimana keadaan mereka. Namun, tidak semua orang mampu memanfaatkan teknologi yang ada secara efektif. Bidang pendidikan misalnya, banyak orang yang menggunakan gawai selama kegiatan belajar mengajar [4].

Selain untuk mengirim pesan dan telepon, perkembangan gawai sekarang tidak hanya digunakan untuk akses internet, jejaring sosial dan playback. Sehingga, daripada belajar, orang lebih memilih menggunakan smartphone. Teknologi yang digunakan secara tidak tepat akan berubah menjadi hal yang mengerikan jika tidak digunakan di lokasi yang sesuai, khususnya di bidang pendidikan[5]. Oleh karena itu, jika smartphone dapat digunakan dengan baik, ini membantu masyarakat untuk belajar [6]. Atas dasar itulah peneliti memiliki berinisiatif mengembangkan media pembelajaran lalu lintas berbasis android.

\section{METODE PENELITIAN}

\subsection{Metode Pengembangan Sistem}

Penelitian dilakukan sesuai dengan metode yang dipilih untuk pengembangan sistem, yaitu Prototipe. Prototipe adalah versi sistem potensial yang akan memberikan wawasan kepada pengembang dan pengguna potensial tentang bagaimana sistem akan beroperasi dalam bentuk yang sudah jadi.[7].

Ide ini didasarkan pada pembuatan prototipe secepat dan bahkan sepanjang malam. Pengguna kemudian menerima umpan balik yang dapat dengan cepat memperbaiki prototipe. [8]. Pendekatan prototipe tidak mengharuskan semua diagram atau model desain menjadi sempurna dan final [9].

Tujuan utama dari persiapan desain adalah untuk menyediakan sistem dengan gambaran materi dan menu, yang perlu dimasukkan dalam prototipe pengembangan [10]. Prototipe mulai berkembang setelah desain terbentuk [11]. Pendekatan prototipe dapat memberikan penjelasan yang lebih rinci kepada pengguna, karena pengguna sering kali mengalami kesulitan pada saat mentransfer kebutuhan mereka secara detail tanpa melihat gambaran yang lebih jelas [12].

Memprediksi bahwa proyek dapat beroperasi sebelumnya, sebaiknya dengan perencanaan, waktu dan biaya. Sebelumnya, pengembang dan pengguna di klien ini harus setuju untuk menentukan persyaratan sistem.

Berikut ialah penjelasan dari tahapan metode prototype:

a. Mengidentifikasi Prototype: Pada tahap ini penulis melakukan pengambilan data di kepolisian resor (POLRES) Kutai Barat guna untuk mengetahui mengenai masalah pelanggaran lalu lintas yang ada dan sering terjadi, kemudian mendapat ide untuk membuat sistem yang dibutuhkan.

b. Mengembangkan Prototype: Bangun prototipe melalui desain sementara yang memfokuskan input dan output.

c. Menentukan apakah prototipe dapat diterima Melakukan penilaian terhadap sistem yang dibangun oleh penulis, apakah sistem yang diinginkan, jika demikian, langkah selanjutnya akan diambil, yaitu pengkodean sistem, jika bukan merupakan revisi dari sistem yang dibangun [13].

d. Menggunakan Prototype: Prototype selesai dibuat dan aplikasi siap untuk dicoba untuk digunakan. 
3. HASIL DAN PEMBAHASAN

\subsection{Hasil Pengembangan Aplikasi}

Menjelaskan tentang tampilan (interface) aplikasi dan layout. Hasil pengemban aplikasi dapat dilihat sebagai berikut:

\subsubsection{Interface Halaman Menu Utama}

Halaman utama merupakan halaman yang akan tampil ketika mengakses sistem. Pada halaman ini terdapat menu yang berisi rambu perigatan, larangan, petunjuk, perintah dan rambu sementara yang dipilih oleh pengguna untuk menuju ke menu ramburambu yang telah dipilih. Tampilan halaman utama dapat dilihat pada gambar 2

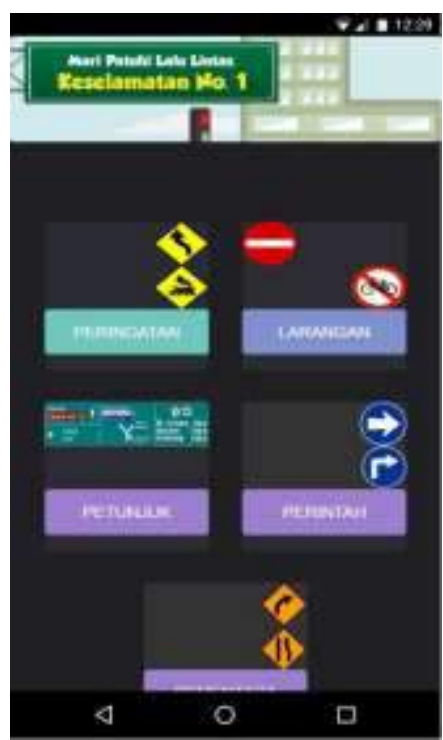

Gambar 2 Halaman Menu Utama

\subsubsection{Halaman Rambu Peringatan}

Halaman tanda peringatan adalah halaman dengan gambar tanda peringatan. Rambu peringatan meliputi 65 rambu yang menginformasikan pengguna jalan tentang kemungkinan bahaya dan sifat bahaya tersebut dalam bentuk peringatan peringatan. Rambu peringatan ditandai dengan rambu dasar kuning dan garis hitam di tepinya serta simbol hitam, huruf dan angka. Gambar 3 menunjukkan tampilan halaman rambu peringatan.

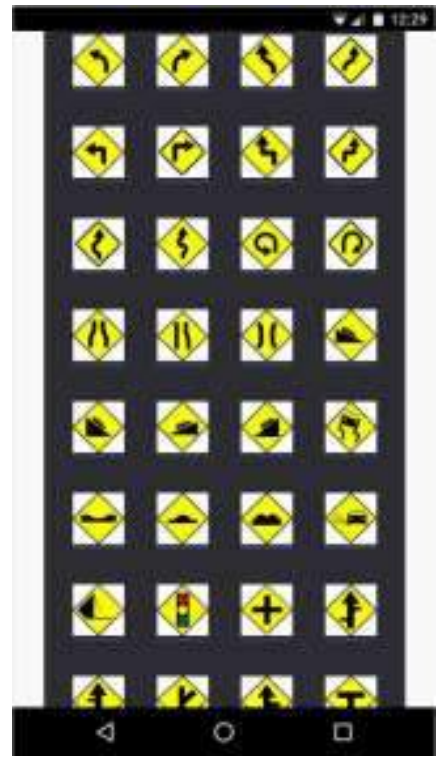

Gambar 3 Tampilan Halaman Rambu Peringatan

\subsubsection{Halaman Rambu Larangan}

Halaman rambu larangan adalah halaman yang menampilkan gambar rambu terlarang. Rambu larangan tersebut antara lain 18 rambu yang menunjukkan larangan bagi pengguna jalan untuk melakukan sesuatu di kawasan tertentu. Rambu lalu lintas larangan menggunakan warna merah dasar putih dan tulisan ataupun lambing warna merah dan hitam. Tampilan halaman rambu larangan dapat dilihat pada gambar 4 .

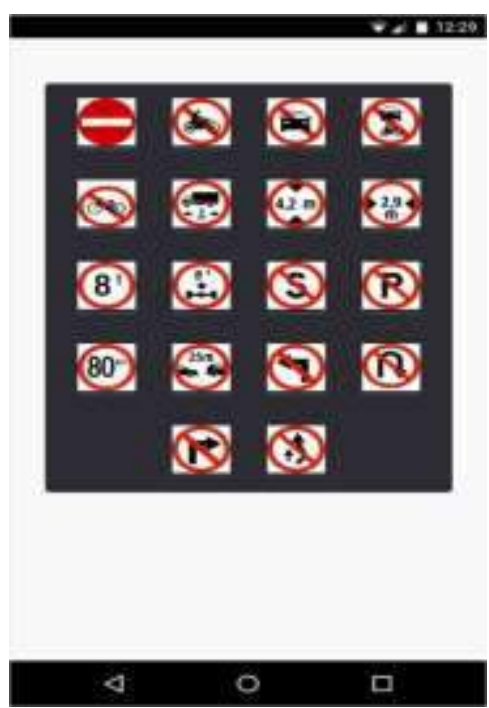

Gambar 4 Tampilan Halaman Rambu Larangan 


\subsubsection{Halaman Rambu Petunjuk}

Halaman yang menampilkan gambar plang adalah halaman plang. Terdapat 68 rambu petunjuk yang memandu pengguna jalan untuk menunjukkan arah, batas dan tempat fasilitas umum. Gambar 5 menunjukkan halaman dengan rambu-rambu panduan.

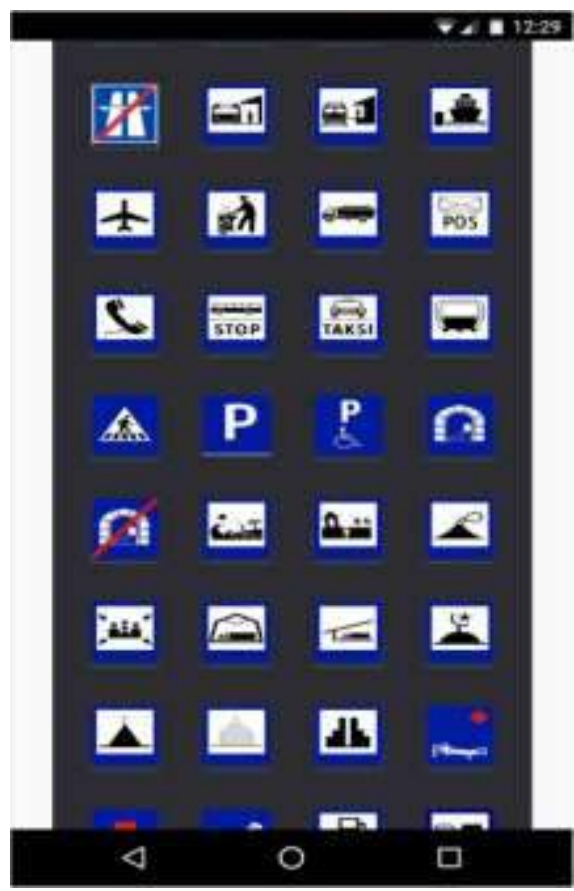

Gambar 5 Tampilan Halaman Rambu Petunjuk

\subsubsection{Halaman Rambu Perintah}

Halaman dengan tanda perintah yang menampilkan gambar tanda perintah adalah halaman. Rambu perintah meliputi 29 rambu yang menandakan perintah agar berkendara lancar dan nyaman bagi setiap pengguna jalan. Tanda kontrol biasanya berwarna dasar biru dan putih dan hitam biasanya digunakan oleh tulisan atau simbol. Halaman tanda larangan yang ditampilkan pada Gambar 6.

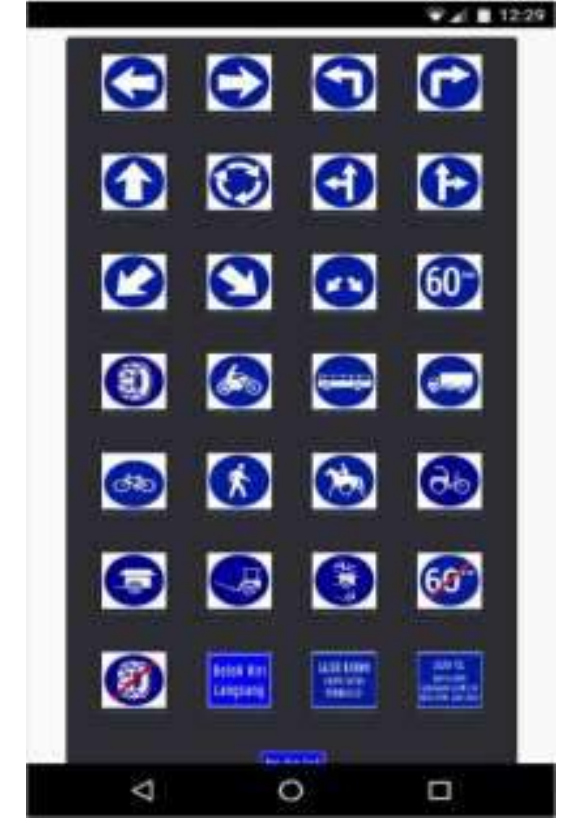

Gambar 6 Tampilan Halaman Rambu Larangan

\subsubsection{Halaman Rambu Sementara}

Halaman Tanda Sementara adalah halaman yang menampilkan gambar tanda sementara. Terpasang dan berlaku untuk satu term saja, rambu-rambu sementara terdiri dari 31 rambu yang bisa dipasang dan dipindahkan setiap saat. Saat jalan diperbaiki atau rintangan tiba-tiba berubah menjadi jalan yang tidak aman. Tanda ini dipasang. Seperti pada Gambar 7 yang menunjukkan tampilan halaman ramburambu sementara.

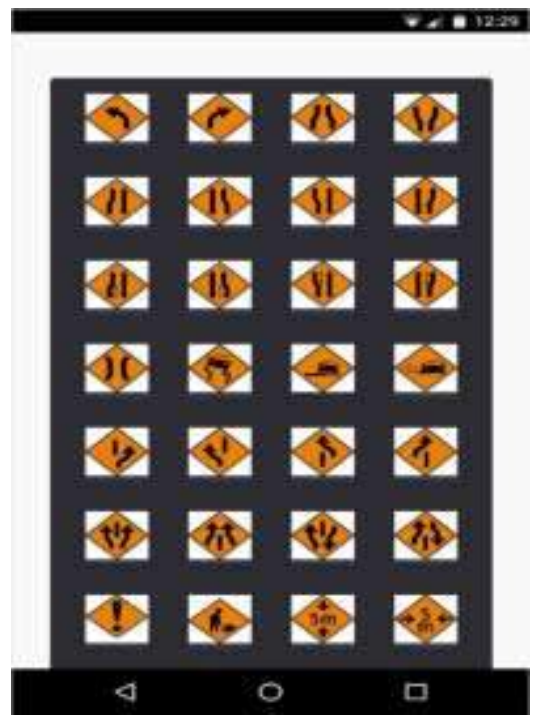

Gambar 7 Tampilan Halaman Rambu Sementara 


\subsubsection{Tampilan Gambar dan Deskripsi Rambu}

Tabel 1 akan menjelaskan bagaimana ketika gambar rambu-rambu pada halaman rambu peringatan, larangan, petunjuk, perintah dan sementara menampilkan gambar beserta deskripsi dari gambar yang dipilih.

Tabel 1. Menampilkan Gambar dan Deskripsi Gambar

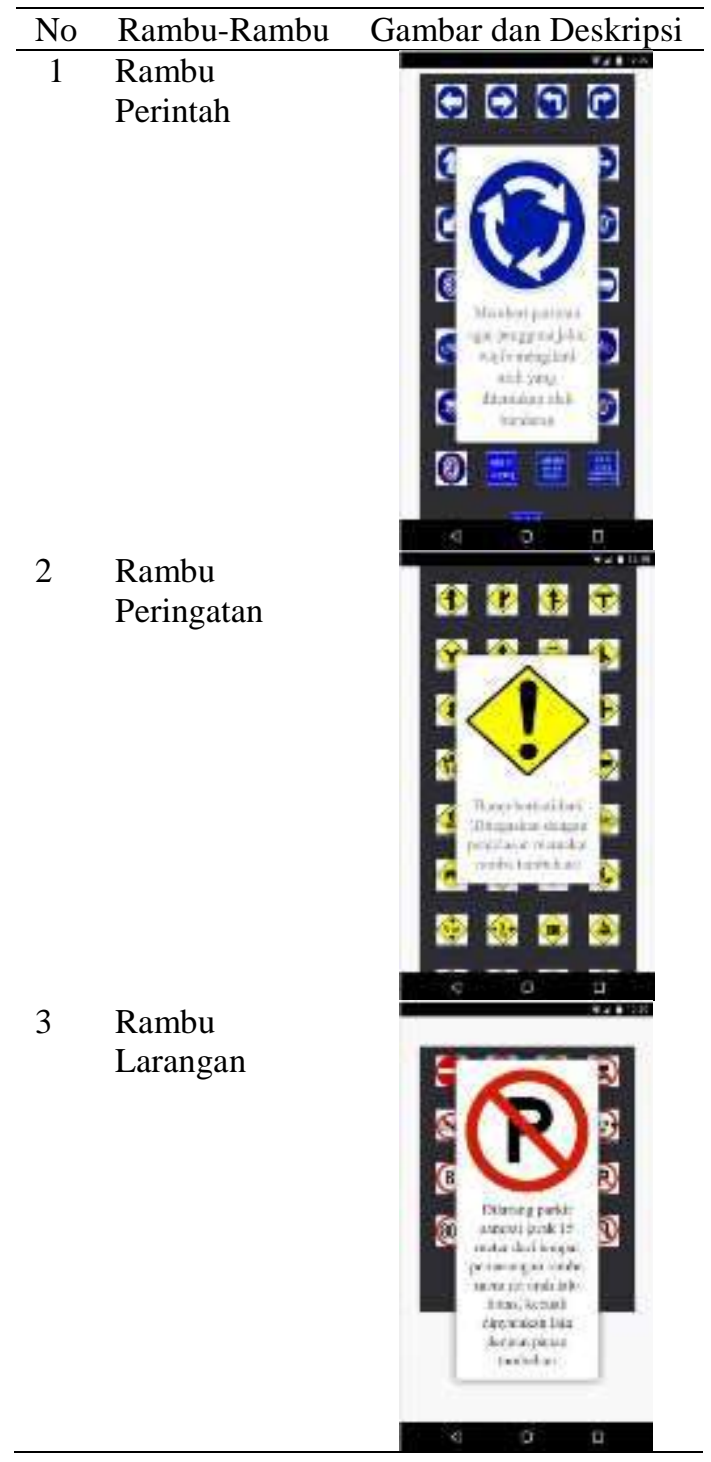

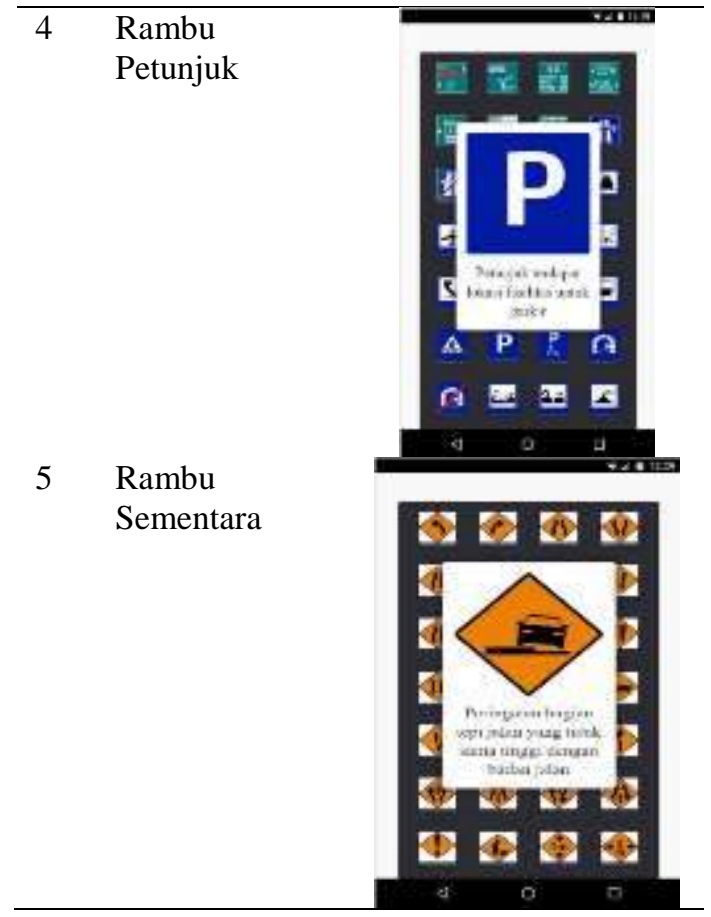

\subsection{Uji Coba Aplikasi}

Setelah pengembangan aplikasi selesai, selanjutnya dilakukan uji coba aplikasi menggunakan metode pengujian black box. Pengujian aplikasi tersebut sebagai berikut:

\subsubsection{Pengujian Sistem}

Setelah aplikasi selesai dibuat maka dilakukanlah proses pengujian. Pengujian sistem adalah proses di mana perangkat lunak dijalankan dan dievaluasi [6]. Pengujian yang dilakukan pada penelitian kali ini ialah metode black box untuk aplikasi pembelajaran rambu lalu lintas Android. Adapun pengujian dilakukan sebagai berikut :

\section{Tabel 2. Pengujian Sistem}

\begin{tabular}{llll}
\hline No & $\begin{array}{l}\text { Komponen } \\
\text { Pengujian }\end{array}$ & $\begin{array}{c}\text { Hasil } \\
\text { Pengujian }\end{array}$ & Kesimpulan \\
\hline & $\begin{array}{l}\text { Memilih } \\
\text { menu }\end{array}$ & $\begin{array}{l}\text { Aplikasi akan } \\
\text { menuju } \\
\text { rambu- } \\
\text { rambu lalu } \\
\text { halaman } \\
\text { lintas } \\
\text { rambu lalu } \\
\text { Perintah, } \\
\text { Peringatan, } \\
\text { Larangan, }\end{array}$ & $\begin{array}{l}\text { Aplikasi } \\
\text { menampilk } \\
\text { an rambu }\end{array}$ \\
dipang dipilih \\
\end{tabular}




\begin{tabular}{|c|c|c|c|}
\hline No & $\begin{array}{l}\text { Komponen } \\
\text { Pengujian }\end{array}$ & $\begin{array}{c}\text { Hasil } \\
\text { Pengujian }\end{array}$ & Kesimpulan \\
\hline & $\begin{array}{l}\text { Petunjuk, } \\
\text { Sementara) }\end{array}$ & & \\
\hline 2 & $\begin{array}{l}\text { Memilih } \\
\text { rambu yang } \\
\text { ada }\end{array}$ & $\begin{array}{l}\text { Aplikasi akan } \\
\text { menampilkan } \\
\text { gambar dan } \\
\text { text }\end{array}$ & $\begin{array}{l}\text { Aplikasi } \\
\text { menampilk } \\
\text { an gambar } \\
\text { rambu yang } \\
\text { dipilih dan } \\
\text { menampilk } \\
\text { an } \\
\text { penjelasan } \\
\text { tentang } \\
\text { rambu } \\
\text { tersebut }\end{array}$ \\
\hline
\end{tabular}

\section{KESIMPULAN}

Prototipe Aplikasi Pembelajaran Rambu Lalu Lintas berbasis Android yang dibangun oleh Penulis beroperasi dengan sangat baik berdasarkan hasil implementasi dan pengujian yang dilakukan. Mulai dari menampilkan menu utama yang berisi rambu peringatan, perintah, petunjuk, larangan dan rambu sementara. Pengguna aplikasi juga dapat melihat gambar rambu lalu lintas dan deskripsi rambu lalu lintas. Dari pembahasan yang sudah diuraikan dapat ditarik kesimpulan bahwa penelitian ini menghasilkan sebuah aplikasi pembelajaran rambu yang memberikan informasi kepada pengendara tentang rambu jalan yang kedepannya siap untuk digunakan oleh masyarakat.

\section{DAFTAR PUSTAKA}

[1] E. I. Wulandari, "Optimalisasi Aplikasi ETilang dalam Penindakan Pelanggaran Lalu Lintas di Polres Banyumas," Adv. Police Sci. Res. J., vol. 4, no. January, pp. 281-328, 2020.

[2] M. N. Irpansyah et al., "Aplikasi pembelajaran aturan lalu lintas berbasis android," pp. 1-9, 2014.

[3] N. Dengen, H. S. Pakpahan, G. F. Putra, M. B. Firdaus, R. Wardhana, and A. Tejawati, "An Augmented Reality Model Physical Transformation Learning," ICEEIE 2019. Int. Conf. Electr. Electron. Inf. Eng. Emerg.
Innov. Technol. Sustain. Futur., pp. 255-259, 2019 , doi: 10.1109/ICEEIE47180.2019.8981444.

K. Lee, "Augmented \{Reality\} in \{Education\} and \{Training\}," Techtrends Tech Trends, vol. 56, no. 2, pp. 13-21, 2012, doi: 10.1007/s11528-012-0559-3.

[5] S. Zare Shahabadi, M. Abbasi Harofteh, and A. Zare Shahabadi, "Relationship of economic and environmental factors with the acceptance of earthen architecture technology: A case study of young educated couples in Yazd, Iran," Technol. Soc., vol. 59, no. December 2018, p. 101152, 2019, doi: 10.1016/j.techsoc.2019.101152.

[6] A. Chavoshi and H. Hamidi, "Social, individual, technological and pedagogical factors influencing mobile learning acceptance in higher education: A case from Iran," Telemat. Informatics, vol. 38, pp. 133165, 2019, doi: 10.1016/j.tele.2018.09.007.

[7] A. Angrish, B. Craver, M. Hasan, and B. Starly, "A Case Study for Blockchain in Manufacturing: 'FabRec': A Prototype for Peer-to-Peer Network of Manufacturing Nodes," Procedia Manuf., vol. 26, pp. 11801192, 2018, doi: 10.1016/J.PROMFG.2018.07.154.

[8] A. Suyatno, T. Informatika, S. Informasi, F. Ilmu, K. Universitas, and D. Bangsa, "METODE PROTOTYPE UNTUK MENINGKATKAN MUTU PELAYANAN SISWA DI SMK KESEHATAN DAARUL HIDAYAH SUKOHARJO," HUBISINTEK 2020, pp. 118-129, 2020.

[9] M. Wichrowski, D. Korzinek, and K. Szklanny, "Google Glass Development in Practice: UX Design Sprint Workshops," Proc. 3Rd Int. Conf. Multimedia, Interact. Des. Innov., 2015, doi: 10.1145/2814464.2814475.

[10] A. Suprapto, "Pengembangan Aplikasi Kuliah Kerja Nyata Pada IAIN Salatiga Dengan Metode Prototype," INFORMAL Informatics $J$, vol. 5, no. 1, p. 1, 2020, doi: 10.19184/isj.v5i1.17328.

[11] S. Paembonan and K. Palopo, "PENERAPAN METODE PROTOTYPE PADA PENGEMBANGAN SISTEM INFORMASI KEPEGAWAIAN DI DINAS KESEHATAN PALOPO," MUSTEK ANIM $H A$, vol. 9, no. 2, 2020.

[12] G. Tendra and D. Wulandari, "Implementasi Representational State Transfer Dan 
Geotagging Pada Aplikasi Pelaporan Kecelakaan Lalu Lintas.," J. Intra Tech, vol. 4, no. 1, pp. 7-16, 2020.

[13] W. Ita Dewi Sintawati, "PENERAPAN METODE PROTOTYPE UNTUK SISTEM INFORMASI PENGADAAN BARANG BERBASIS WEB," J. Chem. Inf. Model., vol. 21, no. 1, pp. 1-9, 2020. 